\title{
Gênero e comportamento eleitoral
}

\author{
Lúcia Avelar
}

ALVES, José Eustáquio Diniz; PINTO, Céli Regina Jardim; JORDÃO, Fátima Pacheco (Orgs.). As mulheres nas eleições 2010. Rio de Janeiro: Associação Brasileira de Ciência Política; Secretaria de Política para as Mulheres da Presidência da República, 2012, 520p.

Um grande feito! Assim poderíamos definir o livro As mulheres nas eleições 2010, uma publicação da Associação Brasileira de Ciência Política e da Secretaria de Política para as Mulheres da Presidência da República. Fruto de um edital público lançado em fevereiro de 2010 pela Secretaria Especial de Política para as Mulheres, ao qual atenderam vários grupos de pesquisadores, a equipe vencedora - o Consórcio Bertha Lutz - acabou por realizar um trabalho de fôlego. Antes de tudo porque é um exemplo de como construir uma ponte para integrar métodos quantitativos e qualitativos na análise de um caso, aprofundando-se, dessa forma, em detalhes dificilmente alcançáveis por uma só estratégia. Além disso, trata-se do primeiro estudo de comportamento eleitoral desenhado e focado na perspectiva de gênero.

Se todo livro tem uma história, este tem uma história peculiar. Ele é o resultado de um longo processo de militância dos movimentos feministas e de mulheres que ganharam força nos últimos 50 anos. A socialização política viera antes, com os movimentos sufragistas e com as organizações isoladas de trabalhadoras, principalmente, do segmento têxtil; depois, nas décadas de 1940 e 1950, houve o aprendizado político vindo das hostes do catolicismo de orientação francesa, com os movimentos estudantis e de trabalhadoras, entre outros. No período da ditadura militar (1964-1985), as mulheres se descobriram feministas ao tomarem consciência de que suas reivindicações não eram ouvidas pelos companheiros de luta política. Mesmo nos movimentos de registro radical, as mulheres foram tratadas como apêndice, senão com autoritarismo machista. Da ditadura à redemocratização e nos anos seguintes, as mulheres se construíram como uma nova força política democrática e autônoma.

\footnotetext{
* Doutora em Ciência Política pela Pontifícia Universidade Católica de São Paulo (1985), pós-doutorado no Departamento de Ciência Política da Yale University nos Estados Unidos, atual pesquisadora associada do Centro de Estudos de Opinião Pública - CESOP/UNICAMP e professora titular de Ciência Política Sênior (lucia_avelar@uol.com.br).
} 
Dos movimentos ao feminismo de Estado, temos toda uma história de criação de organizações e de lutas de gerações de mulheres, até alcançarem representação no Estado. Esse é o caso da Secretaria de Política para as Mulheres. Não fossem o edital e a verba garantida para uma pesquisa abrangente sobre as eleições de 2010 sob a perspectiva de gênero, não haveria como realizar essa pesquisa feita a muitas mãos. A vontade política da ministra Nilcéia Freire foi um fator decisivo.

O livro nos brinda com 15 artigos divididos em três grandes partes: o Eixo 1, composto por três textos sobre comportamento, percepções e tendências do eleitorado brasileiro; 0 Eixo 2, com 11 trabalhos que abrangem o monitoramento das campanhas e candidaturas, na corrida tanto para a Presidência da República quanto para o Senado Federal, a Câmara dos Deputados, os governos e as assembleias estaduais; e o Eixo 3, que trata do monitoramento da mídia jornalística. Tudo isso em um volume de 518 páginas.

Os textos do Eixo 1 abordam dimensões inexistentes nos estudos eleitorais correntes, pois estes supõem neutralidade axiológica. Primeiro porque a variável sexo é trabalhada sistematicamente e, segundo, porque o foco se desloca para temas e abordagens singulares. Dois artigos têm a presença do pesquisador José Eustáquio Diniz Alves, que, de longa data, vem trabalhando com os dados eleitorais das mulheres, acompanhando o crescimento das candidaturas femininas para todos os cargos autorizados pelo voto e colocando à disposição da comunidade, acadêmica e militante, dados e análises que os grupos organizados de mulheres, núcleos de estudos e organizações não governamentais (ONGs) feministas têm utilizado para avaliação dos seus avanços e retrocessos. Em seu artigo solo, ele acompanhou a evolução das intenções de voto para presidente, segundo as variáveis sexo, idade, renda e região, ou seja, algumas variáveis que posicionam os eleitores na estrutura social. Como fonte de dados, o autor utilizou 63 pesquisas nacionais de intenção de voto feitas pelo Ibope, Vox Populi, Sensus e Datafolha. Alves argumenta que a polarizada disputa entre o Partido dos Trabalhadores (PT) e o Partido da Social Democracia Brasileira (PSDB) para a Presidência rompeu-se quando uma mulher, Marina Silva, com seus quase 20 milhões de votos, criou uma "terceira via”, mostrando que o eleitorado está em busca de alternativas além daquelas construídas no período que se seguiu à democratização brasileira.

José Eustáquio Diniz Alves aponta dez fatores que ajudam a entender o crescimento das intenções de voto em Dilma e o fortalecimento da coligação governamental: 1) desejo de continuidade do governo Lula diante dos ganhos obtidos no período de 2004-2008, de expansão da economia com redução da pobreza e da desigualdade; 2) ascensão social e decréscimo das desigualdades e da pobreza; 3) bom desempenho da economia no Nordeste; 4) consolidação da candidatura Dilma no PT; 5) saída de Ciro Gomes e o apoio do Partido Social Brasileiro (PSB); 6) coligação com dez partidos, um trabalho de Lula que ampliou de tal maneira o centro político que a oposição foi neutralizada; 7) palanques estaduais, outra articulação de Lula, induzindo o PT a abrir mão de candidaturas autênticas por aliados, como os do PMDB, garantindo força política em cada Estado; 8) 
recursos financeiros e tempo de propaganda gratuita maiores; 9) apoio de importantes igrejas evangélicas; e 10) apoio efetivo de Lula. Não sem razão, o autor conclui que a Presidência da República, conquistada pela primeira vez por uma mulher, não foi uma vitória do movimento feminista organizado. Outros fatores tiveram peso decisivo e não se reportam às antigas lutas das mulheres.

O artigo "Dilemas do conservadorismo político e do tradicionalismo de gênero no processo eleitoral de 2010: o eleitorado brasileiro e suas percepções”, de autoria de Marlise Matos e Marina Brito Pinheiro, investiga os valores e elementos morais do eleitorado que ainda pesam contra a igualdade de gênero. No survey realizado em outubro de 2010 pelo próprio Consórcio Bertha Lutz, algumas variáveis foram introduzidas e possibilitaram a construção de um conjunto de indicadores de conservadorismo político, confiança em instituições e democracia, além daqueles que visavam mensurar aspectos e dimensões do tradicionalismo de gênero e raça nos espaços públicos e privados no Brasil. Após o debate teórico sobre as teorias da destradicionalização e modernização societária, sobre conservadorismo político e tradicionalismo de gênero, sexualidade e raça, o artigo informa sobre as decisões metodológicas que levaram à construção de dois principais índices: o Índice de Conservadorismo Político (ICP) e o Índice de Tradicionalismo de Gênero (ITG). Utilizando análise fatorial das respostas reunidas nos índices, foi possível afirmar que há diferenças entre homens e mulheres quanto ao tradicionalismo de gênero e ao conservadorismo político. De modo geral, as mulheres apresentaram percepções mais alinhadas a uma postura menos conservadora e mais destradicionalizada do que os homens.

Tais conclusões reafirmam os achados de outros estudos, como o de Katia Nishimura (tese de doutorado, maio de 2009, Unicamp) realizado com os dados do survey Estudos Eleitorais Brasileiros (ESEB) sobre valores, opiniões e atitudes dos brasileiros nas eleições de 2002. Essa autora analisa o conservadorismo na sociedade brasileira e afirma que tal dimensão não se apresenta coerentemente estruturada. Um indivíduo pode ter uma atitude conservadora em relação a homossexualismo e aborto, mas apoiar os novos lugares sociais ocupados pelas mulheres na sociedade. A pesquisa de Matos e Pinheiro reitera os achados de Nishimura, acrescentando para o segmento das mulheres as dificuldades em romper com os papéis tradicionais de gênero. O tratamento dos dados utilizou a análise multivariada e fatorial de variáveis sociodemográficas, de valores, opiniões e atitudes. Entre as primeiras, a escolaridade é, indiscutivelmente, aquela que diferencia os indivíduos: "o ponto de inflexão é a conclusão do ensino médio, observando-se em alguns casos que o curso superior completo predispõe os/as entrevistados/as a terem quase duas vezes mais percepções não tradicionais do que aqueles que cursaram até o primário completo".

Ainda como parte do Eixo 1, Suzana Cavenaghi e José Eustáquio Diniz Alves, utilizando os dados do survey do Consórcio Bertha Lutz, analisam "quem vota em quem”. O estudo levou em conta as características sociodemográficas dos eleitores, como sexo, idade, raça/ cor, grau de instrução, classe social, renda familiar total, condição da atividade laboral, 
região de residência, religião, frequência a culto, recebimento de programa social, variáveis comportamentais resultantes de crenças, ideologias, religiões e outras características culturais, assim como traços individuais dos candidatos tais como honestidade, credibilidade, simpatia, aparência física, sexo, experiência, inteligência, etc. Para a análise, adotou-se uma estratégia metodológica complexa que combinava a modelagem estatística multivariada, modelos de classificação em árvore e modelo logístico multinominal, inquirindo-se qual seria o peso tanto das características individuais dos eleitores, quanto de posturas ideológicas e políticas que afetavam suas escolhas.

O Eixo 2 do livro, intitulado "Monitoramento das campanhas e candidaturas", é um esforço exaustivo para cobrir a campanha de 2010 ao longo de 11 artigos. Seu objetivo é entender como o gênero recortou as eleições presidenciais e se isso teve impacto nos outros níveis eleitorais, influenciando a eleição para governos e Assembleias Estaduais e para a Câmara Federal.

A análise de Fernanda Feitosa, “A participação das mulheres nas eleições de 2010”, procura entender as razões pelas quais o crescimento das candidaturas femininas em nada alterou a representação eleitoral das mulheres. Além disso, mesmo que no primeiro turno da corrida presidencial duas mulheres tenham logrado alcançar $70 \%$ dos votos, isso não suscitou nenhum debate sobre a igualdade racial e de gênero na política. A autora introduz uma discussão sobre o impacto da Lei de Cotas, concluindo que o crescimento de candidaturas femininas não leva ao aumento no número de eleitas.

Bruno Speck e Teresa Sacchet são os autores do capítulo 3 do Eixo 2, em que discutem "patrimônio, instrução e ocupação dos candidatos nas eleições gerais de 2010", arguindo sobre a importância desses recursos no jogo eleitoral. Utilizando a declaração de bens dos candidatos como fonte de dados, os autores mostram que a participação dos homens cresce à medida que seus bens aumentam. Ter herdado ou acumulado grande riqueza talvez não seja garantia de sucesso nas urnas, mas eleva em cinco vezes a chance de se eleger. A instrução mais alta aumenta em 50\% a chance de se eleger, e a ocupação é decisiva nas urnas. Os políticos em cargos eletivos que disputam um novo mandato têm chance cinco vezes acima da média para o sucesso nas urnas. A análise conclui que o impacto da experiência como político tem o mesmo peso que o patrimônio sobre as eleições.

Céli Pinto lançou mão da análise de conteúdo para avaliar os programas eleitorais, os sites e blogs, os programas de governo e as manifestações de apoio às duas candidatas à Presidência. Em seu artigo, a autora defende o argumento de que as candidatas não se identificaram como mulheres durante a campanha eleitoral, o que leva a supor que a estratégia do silêncio quanto à sua condição feminina seria uma via mais segura para a conquista dos votos. Os direitos da mulher, da criança, do adolescente e dos idosos ficaram ausentes do debate, bem como a questão da violência contra a mulher. No programa de Dilma, tais referências tiveram registro, mas não na campanha, uma oportunidade pedagógica completamente perdida. A análise conclui que houve um trabalho de anulação ou apagamento discursivo da condição de mulher na propaganda. 
A análise das candidaturas para o Poder Executivo estadual ficou a cargo das pesquisadoras Maria Beatriz Nader e Lívia Rangel. Como fontes de dados, as autoras recorreram aos sites e blogs dos candidatos, acompanhando a interatividade entre eleitores e apoiadores. As informações obtidas permitiram observar aspectos como profissão, questão regional, militância política, pertencimento partidário, inserção em coligações, exercício de cargos públicos, eficácia ou não do capital político acumulado, votação e colocação das candidatas pesquisadas, bem como seu alinhamento ou não com o governo federal. Entre outros achados, elas reiteram conclusões de outros estudos, como a enorme vantagem dos candidatos eleitos para mandatos anteriores. Ao monitorar 27 temas presentes na campanha, as autoras concluem que as candidatas aos cargos executivos estaduais mostram um perfil de preferências temáticas semelhante ao dos homens, passando ao largo dos temas da desigualdade de gênero, da violência contra a mulher e da sub-representação política.

O estudo analisando as candidaturas femininas ao Senado ficou a cargo do grupo de pesquisadoras da Universidade Federal da Bahia (UFBA) e do Núcleo Interdisciplinar sobre a Mulher (Neim): Sonia Wright, Eulália Lima Azevedo e Joselita Santana. Também a partir dos sites e blogs das candidatas, as autoras realizaram uma ampla análise contextual sobre as candidaturas femininas nos respectivos Estados e regiões, ressaltando, logo de início, o baixo número de candidatas em comparação ao de homens, em continuidade com o padrão histórico-eleitoral das candidaturas para aquela instância. Entre as oito senadoras eleitas em todo o território nacional, o que elas têm em comum é sua alta escolaridade e o exercício de profissões de alta qualificação - como economista, psicanalista, advogada e farmacêutica. Suas conclusões confluem para achados de outros estudos, como o fato de que os partidos maiores, como o PMDB, são mais avessos ao recrutamento de mulheres para os cargos mais altos, no geral ocupados pelos caciques dos partidos. Diferentemente do que se concluiu para as mulheres candidatas para os outros cargos, surpreendentemente, a maioria das candidatas ao Senado defende os direitos das mulheres, ao passo que nenhum candidato homem compromete-se com essa questão.

O capítulo 7 do Eixo 2 é "Cotas e movimentos sociais nas estratégias partidárias de inserção das mulheres na vida parlamentar: os casos do Rio de Janeiro e Ceará nas eleições de 2010 para a Câmara dos Deputados”. Os autores Fabiano dos Santos (lesp/Uerj), Carolina de Paula (doutoranda) e Joana Seabra (mestranda) desenvolveram um modelo analítico para averiguar o grau de consistência dos partidos na formulação das listas de candidatas e seu impacto sobre a possibilidade de se elegerem mulheres. As questões subjacentes eram: "qual o grau de abertura dos partidos às candidaturas femininas? Sua inserção como candidatas devia-se apenas ao cumprimento legal da Lei de Cotas?".

O recrutamento partidário foi visto sob a ótica de duas variáveis: as estratégias gerais de recrutamento; e as estratégias de recrutamento direcionadas para mulheres. No segundo caso, verificou-se a existência ou não de estratégias específicas para as mulheres. Na participação das mulheres na instituição partidária, a análise foi feita mediante duas variáveis: movimentos 
institucionais das mulheres no interior da legenda; e mulheres ocupando cargos de direção na legenda.

De todos os partidos, as siglas do PT e do PCdoB apresentaram consistência pró-gênero por serem partidos que, de acordo com os dirigentes partidários, se organizam em torno de movimentos sociais.

"Presença e ausência de candidatas: mapeando representações de dirigentes partidários", artigo das pesquisadoras Irlys Barreira e Daniyelle Gonçalves, utiliza entrevistas e sites dos partidos como fontes de informação. O objetivo foi o de captar as contradições entre as percepções individuais dos dirigentes e a realidade da desigualdade da participação feminina nas organizações partidárias. Reafirmam as bases de recrutamento de seus membros, sendo os movimentos sociais e associações as instâncias principais de onde vêm as candidaturas femininas. As autoras apontam o desconforto dos dirigentes partidários com a Lei de Cotas, que veio para atrapalhar: são muitas as exigências burocráticas, e ineficazes na ampliação da representação feminina. Alguns dirigentes partidários reconhecem que as cotas favorecem o debate sobre a participação feminina e conscientizam sobre a desigualdade de gênero, mas o jogo partidário continua sendo "muito masculino e inescrupuloso, muito pragmático", segundo uma das entrevistadas.

O artigo de Clara Araujo e Doriam Borges, "O gênero, os elegíveis e os não-elegíveis: uma análise das candidaturas para a Câmara Federal em 2010”, oferece um quadro de acompanhamento dos candidatos com mediação de gênero, as principais barreiras e os estímulos que acompanham o percurso, desde as potenciais candidaturas e a seleção dos elegíveis até a eleição efetiva. A unidade de análise são os próprios candidatos ao cargo. Os procedimentos metodológicos usados abrangeram: pesquisa amostral, na qual se utilizou questionário estruturado junto a candidatos de 14 Estados; dados sociodemográficos retirados do TSE; resultados eleitorais traduzidos em votos; dados relativos à prestação de contas de campanha oficialmente informada ao TSE pelos candidatos; e dados do próprio Consórcio Bertha Lutz relacionados com o acompanhamento do Horário Gratuito de Propaganda Eleitoral, como o tempo de exposição de cada candidato, de modo a relacionar os recursos com os potenciais elegíveis. Após uma descrição do perfil sociodemográfico e vínculos sociais dos entrevistados, analisaram-se as motivações nos caminhos da inserção partidária e eleitoral, procurando responder às seguintes questões: "por que determinadas pessoas se motivam a disputar um processo eleitoral e outras não? Por que, proporcionalmente, menos mulheres se dispõem a fazê-lo?”.

Os autores observam que a importância do histórico familiar parece reduzir-se ao longo do tempo, sugerindo maior institucionalização e diversificação de caminhos. Quanto aos recursos vindos de trajetórias e experiências públicas, os homens possuem mais experiência em todos os tipos de cargos mencionados. Mas, surpreendentemente, as mulheres demonstraram menor descontentamento com as organizações partidárias durante a campanha. Os homens citam outras redes de apoio. 
As "Assimetrias de gênero nas campanhas eleitorais para a Câmara Federal” foram analisadas por Maria das Dores Campos Machado e Rosanete Steffenon, docente e mestranda da Escola de Serviço Social da Universidade Federal do Rio de Janeiro (UFRJ). Ao longo do estudo qualitativo feito a partir de três fontes de dados - os sites e/ou blogs das candidaturas, o Horário Gratuito de Propaganda Eleitoral e o survey realizado junto a 260 nomes sorteados de candidatos -, as autoras contemplam, com minúcia, o peso de cada recurso de campanha na eleição de 2010. Elas avaliaram o peso dos sites e blogs para candidatos homens e mulheres, mostrando que a assimetria de gênero se reproduz também nos recursos tecnológicos utilizados. Os homens, muito mais que as mulheres, exploram mais amplamente as referências visuais. Os vídeos expostos pelos homens mostravam mais sofisticação, se comparados aos das mulheres. Por quê? A inexperiência das mulheres, seu déficit de recursos e o menor apoio intrapartidário talvez sejam alguns dos fatores que podem explicar a referida assimetria. As biografias políticas analisadas mostram diferenças na natureza da militância, já que a estudantil, a sindical e a partidária foram maiores entre os homens, enquanto para as mulheres destacaram-se movimentos de mulheres e feministas, associações sindicais, movimentos dos sem-terra, movimento negro, movimentos religiosos e, por último, agremiações partidárias e projetos sociais. Sabemos que os grupos de militância indicados pelos homens se traduzem em maior número de votos, ao passo que os das mulheres, em geral movimentos de base, de minorias, nem sempre se expressam em ganhos eleitorais.

Em "Dinheiro e sexo na política brasileira: financiamento de campanha e desempenho eleitoral em cargos legislativos”, artigo de Teresa Sacchet e Bruno Speck, é analisada a relação entre o financiamento de campanha e o desempenho eleitoral dos candidatos. Após um amplo debate sobre a importância dos recursos financeiros em processos eleitorais, os autores chamam atenção também para o fato de que os recursos financeiros têm importância já na definição das candidaturas pelos partidos. Isso se alia ao capital social e político do candidato, ao seu mais alto status e à sua trajetória ou biografia política, como o fato de ter ocupado anteriormente cargos públicos, de ter seu nome conhecido.

Os autores justificam a escolha pelas eleições proporcionais: nelas é que os candidatos competem entre si na mesma sigla partidária, diferentemente do que ocorre nas eleições majoritárias, nas quais os partidos devem se empenhar em favor do candidato escolhido. Eles mostram a diminuição de chance de eleição das mulheres após a introdução das cotas, em termos numéricos, porque antes delas o número de concorrentes era menor. À medida que aumentam proporcionalmente as candidaturas femininas, diminui a chance de eleição das mulheres, o que aponta para a necessidade de implementação de outras medidas para que a disputa seja mais equânime.

A correlação entre financiamento e sucesso eleitoral é alta. Evidenciou-se a desvantagem das mulheres em quase todas as fontes de financiamento. Destaca-se o caso do PSB: nesse partido as campanhas das mulheres foram $47 \%$ superiores às dos homens. No geral, foi 
nos partidos menores e de esquerda que o financiamento das candidaturas femininas ficou próximo ou superior ao dos homens.

O artigo "Participação feminina e dinâmica da campanha no Horário Gratuito de Propaganda Eleitoral (HGPE) nas eleições 2010 para a Câmara dos Deputados” foi elaborado por Karolyne Romero, Marcus Figueiredo e Clara Araujo. A fonte de dados foi uma pesquisa coordenada por Marcus Figueiredo e realizada no Laboratório de Pesquisa em Comunicação Política e Opinião Pública (Doxa/lesp/Uerj), que cobriu os quatro níveis de competição nas eleições de 2010. 0 artigo aborda apenas os resultados para a Câmara dos Deputados. Os Estados analisados foram selecionados conforme sua representatividade regional e partidária: Alagoas, Amapá, Bahia, Ceará, Distrito Federal, Goiás, Maranhão, Minas Gerais, Pernambuco, Paraná, Rio de Janeiro, Rio Grande do Norte, Rondônia, Roraima, Rio Grande do Sul, Santa Catarina, Sergipe e São Paulo. Foram acompanhados 16.271 programas distribuídos por 2.230 candidatos.

O trabalho mostra, antes de tudo, como a ocupação do espaço no HGPE é seletiva, com clara preferência pelos candidatos masculinos. A sub-representação feminina no conjunto das candidaturas fica potencializada na propaganda eleitoral. Não só é menor o número de mulheres que comparecem, mas também são menores os recursos, a frequência e o tempo destinados a elas. Quanto às demandas técnicas, que requerem maiores custos - tais como efeitos especiais e computação gráfica -, são os homens que as utilizam preferencialmente.

Marisa Sanematsu e Jacira Vieira de Melo, responsáveis pela análise do Eixo 3 do livro, apresentam a "Cobertura sobre mulheres na política nas eleições de 2010: uma oportunidade perdida de aprofundar o debate”. Para tanto, as autoras acompanharam a produção editorial de 29 jornais impressos e de circulação diária, quatro revistas semanais e quatro telejornais no período de julho a outubro de 2010. A abordagem metodológica utilizada foi análise de conteúdo. A chamada no título do artigo aponta para o fato de que, mesmo com duas fortes candidatas na competição eleitoral, não se aprofundou nenhum tema relacionado com as demandas feministas, como a sub-representação feminina, a violência contra a mulher, o aborto, cotas por sexo, recursos dos fundos partidários ou tempo de propaganda. O tema do aborto foi usado de modo distorcido e polarizado, como uma questão moral que poderia levantar suspeitas sobre quem o defendesse. As candidatas se fixaram nas propostas para as áreas da saúde, educação e desenvolvimento. Na mídia jornalística, o único aspecto que ganhou realce foi a presença de duas candidatas com densidade política e forte expressão eleitoral. Nada mais.

Para a classificação das matérias as autoras utilizaram questões específicas sobre desigualdades entre homens e mulheres no campo político, menção a políticas públicas, menção a legislação, abrangência geográfica do tema citado e foco central da notícia (candidatura, eleitorado, agenda política). Elas mostram que houve predomínio masculino na autoria dos textos, que as eleitoras receberam pouca atenção, que o tema da violência contra a mulher foi tratado transversalmente, que o aborto foi usado como arma eleitoral. 
Para concluir, o que temos a acrescentar é a utilidade dessa publicação para os estudiosos do comportamento eleitoral e dos estudos de gênero. Trata-se, também, de uma referência para "construir a ponte”, integrando métodos quantitativos e qualitativos na análise de caso, tal como vêm pregando a epistemologia feminista e os metodólogos preocupados com os métodos mistos, tais como McBride e Mazur (2005; 2006).

\section{Referências}

McBRIDE, D.; MAZUR, A. Building a (data) bank while crossing the bridge: RNGS strategies to integrate qualitative and quantitative methods. British Journal of Political Science Conference. Londres, Junho, 2006.

The comparative study of women's movements: conceptual puzzles and RNGS solutions. In: AMERICAN POLITICAL SCIENCE ASSOCIATION CONFERENCE. Washington (DC), Set. 1-4, 2005.

Recebido para publicação em 17/02/2013

Aceito para publicação em 23/05/2013 